\title{
Complex tauopathies vs. tangle predominant dementia
}

\author{
Response to the Letter from Professor Kurt Jellinger
}

\author{
Gabor G. Kovacs $\cdot$ Herbert Budka
}

Received: 5 September 2011 / Accepted: 5 September 2011/Published online: 14 September 2011

(c) Springer-Verlag 2011

We are grateful to Professor Jellinger for his comments. In Table 3 of our paper [1], we thought it would be useful to summarize only the salient histopathological features of entities that would be considered for a differential diagnosis. As with all such didactic tables, not all features of lesser importance could be listed. Indeed, Iseki et al. [2] mentioned thorn-shaped astrocytes in the CA1 subregion in neurofibrillary tangle predominant dementia (NFTD), but Jellinger and Bancher [3] indicated that "Tau-IR astroglial inclusions, such as tufted astrocytes (...) and astrocytic plaques (...) were rarely observed on reexamination of personal cases". In another paper, Jellinger and Attems [4] mentioned tufted astrocytes as a rare phenomenon similar to Alzheimer disease, and astrocytic plaques as rare/occasional. However, we agree with Professor Jellinger that the astrogliopathy in the complex tauopathy described by our group [1] differs from that described in NFTD both morphologically and on the level of anatomical distribution. While ghost tangles are a very important component of the neuropathology of NFTD, our cases of the complex tauopathy only occasionally exhibited these, which thus were not included in Table 3.

We hope that further cases of the complex tauopathy will be reported. Indeed, in the follow-up of the VITA study that initiated us to report these cases, we have already observed further cases. It is a challenge not only to consider and diagnose such cases, but also to understand still more the pathobiological basis of such peculiar neurodegenerative constellations.

\section{References}

1. Kovacs GG, Molnar K, Laszlo L, Ströbel T, Botond G, Hönigschnabl S, Reiner-Concin A, Palkovits M, Fischer P, Budka $\mathrm{H}$ (2011) A peculiar constellation of tau pathology defines a subset of dementia in the elderly. Acta Neuropathol 122:205-222

2. Iseki E, Yamamoto R, Murayama N, Minegishi M, Togo T, Katsuse O, Kosaka K, Akiyama H, Tsuchiya K, de Silva R, Andrew L, Arai H (2006) Immunohistochemical investigation of neurofibrillary tangles and their tau isoforms in brains of limbic neurofibrillary tangle dementia. Neurosci Lett 405:29-33

3. Jellinger KA, Bancher C (1998) Senile dementia with tangles (tangle predominant form of senile dementia). Brain Pathol 8: 367-376

4. Jellinger KA, Attems J (2007) Neurofibrillary tangle-predominant dementia: comparison with classical Alzheimer disease. Acta Neuropathol 113:107-117
G. G. Kovacs $(\bowtie) \cdot$ H. Budka

Institute of Neurology, Medical University Vienna, AKH 4J, Währinger Gürtel 18-20, 1097 Vienna, Austria

e-mail: gabor.kovacs@meduniwien.ac.at 